\title{
Placing on the market of novel foods or novel ingredients in Europe "novel food procedure"
}

\author{
Carole KOHLER \\ Conseil Alimentation Santé, \\ 35 rue des Equarts, \\ 79000 Niort, France \\ <carolekohler@club-internet.fr>
}

\begin{abstract}
Novel Foods » concerned foods and food ingredients that have not been used for human consumption to a significant degree within the Community before 15 May 1997. Regulation (EC) No 258/97 of 27 January 1997 lays out detailed rules for the authorisation of novel foods and novel food ingredients. In order to ensure the highest level of protection of human health, novel foods must undergo a safety assessment before being placed on the EU market. The application must be in accordance with Commission Recommendation 97/618/EC concerning the scientific information and the safety assessment. A proposal of the revision of this regulation of has been adopted in order to reflect the fact that genetically modified (GM) food no longer falls under its scope, to create a more favourable legislative environment for innovation in the food industry, and to better facilitate foodstuffs trade between Europe and the rest of the world. The consumer would also benefit from a wider choice of safe novel foods.
\end{abstract}

Key words: novel food, regulation (EC) No 258/97, GM food, authorisation, safety

obtained by traditional propagating or breeding practices and having a history of safe food use;

- foods and food ingredients to which has been applied a production process not currently used, where that process gives rise to significant changes in the composition or structure of the foods or food ingredients which affect their nutritional value, metabolism or level of undesirable substances.

The regulation is not applicable to:

- food additives, falling within the scope of Council Directive 89/107/EEC of 21 December 1988 [2];

- flavourings for use in foodstuffs, falling within the scope of Council Directive 88/388/EEC of 22 June 1988 [3];

- extraction solvents used in the production of foodstuffs, falling within the scope of Council Directive 88/344/EEC of 13 June 1988 [4].

\section{GMO's}

food ingredients that have not been on EU market to a significant degree before May 1997 and that fall under the following categories:

- foods and food ingredients with a new or intentionally modified primary molecular structure;

- foods and food ingredients consisting of or isolated from micro-organisms, fungi or algae; - foods and food ingredients consisting of or are isolated from plants or isolated from animals; except for food and food ingredients
Since 2003, most GMOs have been approved under regulation (EC) No 1829/2003 [5]. New $\mathrm{GMO}$ maizes, applications for the marketing of which were submitted under Regulation (EC) No 258/97, have been authorised. Their labelling is based on regulation (EC) No 1829/2003 and they are subject to the traceability requirements established by Regulation (EC) No 1830/2003 [6].

\section{Notified foods}

Novel foods or novel food ingredients may follow a simplified procedure, only requiring notifications from the company, when they are considered by a national food assessment body as "substantially equivalent" to existing foods or food ingredients (as regards their composition, nutritional value, metabolism, intended use and the level of undesirable substances contained therein).

\section{Application report}

Companies that want to place a novel food on the EU market need to submit their application in accordance with Commission Recommendation 97/618/EC [7] that concerns the scientific information and the safety assessment report required.

The identification of essential information for assessment is guided by eight structured schemes provided the information required to support the safety and nutritional evaluation of the novel food:

I. Specification of the novel food.

II. Effect of the production process applied to the novel food.

III. History of the organism used as the source of the novel food.

IX. Anticipated intake/extent of use of the novel food.

$X$. Information from previous human exposure to the novel food or its source.

XI. Nutritional information on the novel food. 
XII. Microbiological information on the novel food.

XIII. Toxicological information on the novel food

\section{Evaluation procedure}

Before being placed on the market, the foods and foods ingredients referred to in the regulation must undergo Community assessment, as a result of which an authorisation decision may be taken.

Under the assessment procedure, the applicant (manufacturer, retailer...) must submit his application to the Member State which will market for the first time the Novel foods. Hence, the competent body of the Member State which receives the application must make an initial assessment and determine whether or not an additional assessment is required. If neither the Commission, assisted by the Standing Committee on the Food Chain and Animal Health ${ }^{1}$ nor the Member States raise an objection, and if no additional assessment is required, the Member State informs the applicant that he may place the product on the market.

In other cases the Commission must take an authorisation decision with the assistance of the Standing Committee for Foodstuffs. Any decision or provision concerning a novel food or food ingredient which is likely to have an effect on public health must be referred to the Scientific Committee for Food.

The experience is all too be aware of the lenght of this procedure, in average 2 to 6 years. It should be mentionnned as well that the choice of the member state is important. In fact, the evaluation systems of the different authorities are not equivalent: some countries such as Belgium and UK offer a cooperative but charged approach with the applicant, around 3000 to $4000 €$ for a complete dossier.

\section{Authorisations}

The authorisation decision defines the scope of the authorisation and specifies, as appropriate, the conditions of use, the designation of the food or food ingredient, its specification and the specific labelling requirements.

A total of 80 applications $^{2}$ have been made between May 1997 and March 2008 including the GM foods applications. Three categories of Novel foods are in practice requested:

\footnotetext{
${ }^{1}$ Health \& Consumer Protection Directorate General (DG SANCO). http://ec.europa.eu/dgs/health_ consumer/index_fr.htm.

2 The liste of Applications for Authorisation of nove foods. http://ec.europa.eu/food/food/biotechnology/ novelfood/index_en.htm.
}

Table 1. Novel food lipids: authorised and under evaluation (june 2008).

\begin{tabular}{|ll|}
\hline Novel food lipids authorised & Novel food lipids under evaluation (june 2008) \\
\hline - Yellow fat spreads with added phytosterol- & - Vegetable oil from Inca Inchi (Plukenetia volubilis \\
esters, & linneo), \\
- DHA-rich oil, & - Conjugated Linoleic Acid (CLA), \\
- Rapeseed oil high in unsaponifiable matter, & - Triterpene rich Shea Butter Unsaponifiables, \\
- Maize germ oil high in unsaponifiable matter, & - Lipid extract from Euphausia superba, \\
- ENOVA'M-oil, Diacylglycerol Oil (DAG oil), & - Cis-9-cetyl myristoleate \\
- MultOils (oil containing a diacylglycerol-rich & - Tomato oleoresin containing lycopene for use in foods \\
fat component and a free phytosterol esters & for special medical purposes and food uses \\
component). & - Synthetic lycopene in sunflower oil dispersion \\
- Diminicol, phytosterol enriched fat ingredient & - Additional uses of DHA (docahexaenoic acid)-rich oil \\
- Refined Echium oil (Echium plantagineum), & from microalgae Ulkenia sp. \\
- Allanblackia seed oil for use in yellow fat & - Fungal Oil SUN-TCA40S \\
spread and cream based spreads, & \\
- Oil enriched with phytosterols/phytostenols. & \\
\hline
\end{tabular}

- innovative food (e.g. phystosterols foodstuffs, threhalose, phospholipids isolated from egg yellow);

- traditional food from third countries (e.g. noni juice);

- food produced by new production techniques with possible impact on food (e.g. highpressure pasteurised fruit juice).

For 20 products the application of the placing on the market was withdrawn or was refused (e.g. nangai nuts, Stevia rabaudiana); and for 140 products the notification ${ }^{3}$ of the placing on the market was recognised (e.g. argan oil).

By March 2008, thereby $37 \%$ of novel foods requested have been approved to be commercialised in the Europe. Novel food lipids are representating respectively $7.5 \%$ of the total of applications and about $20 \%$ of the novel foods authorised (table 1).

\section{Review of Regulation (EC) No 258/97}

A revision of the Novel Food Regulation is deemed necessary in order to reflect the fact that genetically modified (GM) food no longer falls under its scope, to create a more favourable legislative environment for innovation in the food industry, and to better facilitate both internal and external trade in foodstuffs. An online consultation ${ }^{4}$ on the revision of Novel Food Regulation (EC) No 258/97 was

\footnotetext{
${ }^{3}$ The liste of Notifications of novel foods. http://ec.europa.eu/food/food/biotechnology/ novelfood/notified_en.htm.

${ }^{4}$ Responses to the online consultation on the revision of novel food regulation EC 258/97, Summary report on the impact assessment for a Regulation replacing Regulation (EC) no 258/97 on novel foods and novel food ingredients, Report on impact assessment for a Regulation replacing Regulation (EC) no
}

launched by the European Commission, to gather input from the general public, stakeholders and Member States in order to carry out an impact assessment for a future legislative proposal to revise the current Novel Food Regulation.

From the 14th of January 2008, the European Commission has adopted a proposal $(\operatorname{COM}(2007) 872)^{5}$ to revise the Novel Foods Regulation (EC) No 258/97 with a view to improving the access of new and innovative foods to the EU market, while maintaining a high level of consumer protection and ensuring food safety. Under the draft regulation, novel foods would be subject to centralised authorisation procedure. The Commission will receive the application for authorisation and the European Food Safety Authority (EFSA) ${ }^{6}$ will carry out the scientific assessment on the product.

The "one door - one key" approach will be taken for the approval of novel foods, just as it will be for food additives, food enzymes and food flavourings. This means that the applicant may make one application for approval covering all these possible uses of the substance in question.

The proposal also sets out data protection rules, which aim to protect newly developed foodstuffs once authorised, and encourage companies to invest in developing new types of foods and food production techniques. More-

258/97 on novel foods and novel food ingredients. http://ec.europa.eu/food/food/biotechnology/ novelfood/initiatives en.htm.

${ }^{5}$ COM(2007)872: Proposal for a Regulation of the European Parliament and of the Council on novel foods and amending Regulation (EC) No $x x x / x x x x$ [common procedure]. http://ec.europa.eu/food/ food/biotechnology/novelfood/index_en.htm. ${ }^{6}$ Official website of the European Food Safety Authority (EFSA). http://www.efsa.europa.eu/EFSA/ efsa_locale-1178620753812 home.htm. 
over, a notification procedure is introduced for foods which have not been traditionally sold in the EU but which have a safe history of use in third countries.

\section{Conclusion}

In practice, novel foods are newly developed innovative foods and foods produced by new technologies with possible impact on food, as well as exotic traditional foods from outside the EU. Since 2004, GM foods are separately regulated by Regulation (EC) No 1829/2003.

The EU has since 1997 received 80 applications for approval from more than 45 companies (GM foods included). Over recent years, 7-10 applications per year have been submitted. The consultation from 2002 to 2007 of the main stakeholders has underlined the importance of and the need to develop and update the regulation; in order to streamline the authorisation procedure, develop a more adjusted safety assessment system for traditional food from third countries, and to improve the efficiency, transparency and application of the authorisation system.

The proposal of the revision of regulation has been adopted in January 2008. Normally, the revision of this regulation shall not enter into force before 2010. Thus, the companies would benefit of a more favourable legislative environment for innovation in the food industry, and of a better foodstuffs trade between
Europe and the rest of the world. The consumer would also benefit from a wider choice of safe novel foods.

\section{REFERENCES}

1. EUROPEAN PARLIAMENT AND OF THE COUNCIL. Regulation (EC) No 258/97 of the European Parliament and of the Council of 27 January 1997 concerning novel foods and novel food ingredients. OJL 043, 14/02/1997, p. 0001-6) http://eurlex.europa.eu/LexUriServ/LexUriServ.do?uri= CELEX:31997R0258:EN:HTML.

2. EUROPEAN COUNCIL. Council Directive $89 / 107 /$ EEC of 21 December 1988 on the approximation of the laws of the Member States concerning food additives authorized for use in foodstuffs intended for human consumption. OJL 40, 11/2/1989, p. 27-33) http://eurlex.europa.eu/LexUriServ/LexUriServ.do?uri= CELEX:31989L0107:EN:HTML.

3. EUROPEAN COUNCIL. Council Directive $88 / 388 /$ EEC of 22 June 1988 on the approximation of the laws of the Member States relating to flavourings for use in foodstuffs and to source materials for their production. OJL 184, 15/7/1988, p. 61-6 http://eurlex.europa.eu/LexUriServ/LexUriServ.do? uri=CELEX:31988L0388:EN:HTML.

4. EUROPEAN COUNCIL. Council Directive 88/344/EEC of 13 June 1988 on the approximation of the laws of the Member States on extrac- tion solvents used in the production of foodstuffs and food ingredients. OJL 157, 24/6/1988, p. 28-33) http://eur-lex.europa.eu/LexUriServ/ LexUriServ.do?uri=CELEX:31988L0344:EN:HTML.

5. EUROPEAN PARLIAMENT AND OF THE COUNCIL. Regulation (EC) No 1829/2003 of the European Parliament and of the Council of 22 September 2003 on genetically modified food and feed, (O) L 268, 18/10/2003, p. 1-23) http://eurlex.europa.eu/LexUriServ/LexUriServ.do?uri= CELEX:32003R1829:EN:HTML.

6. EUROPEAN PARLIAMENT AND OF THE COUNCIL. Regulation (EC) No 1830/2003 of the European Parliament and of the Council of 22 September 2003 concerning the traceability and labelling of genetically modified organisms and the traceability of food and feed products produced from genetically modified organisms and amending Directive 2001/18/EC, (O) L 268, 18/10/2003, p. 24-28) http://ec.europa.eu/environment/biotechnology/ pdf/regu1830_2003.pdf.

7. EUROPEAN COMMISSION. Commission Recommendation 97/618/EC of 29 July 1997 concerning the scientific aspects and the presentation of information necessary to support applications for the placing on the market of novel foods and novel food ingredients and the preparation of initial assessment reports under Regulation (EC) No 258/97 of the European Parliament and of the Council, (O) L 253, 16/09/1997, p. 0001 - 0036). http://eurlex.europa.eu/LexUriServ/LexUriServ.do?uri= CELEX:31997H0618:EN:HTML. 